\title{
Discussion on the Cultivation of New-Type Professional Farmers
}

\author{
Zhang Wei \\ School of Humanities \\ Tianjin Agriculture University \\ TJAU \\ Tianjin, China \\ Willazhang312@163.com
}

\author{
Liu Hongyin \\ School of Humanities \\ Tianjin Agriculture University \\ TJAU \\ Tianjin, China \\ lhy813@163.com
}

\begin{abstract}
With reform progressing, cultivating new-type professional farmer became the crucial needs of China. Presently, many problems appear in professional farmer cultivation. Our objectives in this paper are to exam causes and find out solutions for the problems. By utilizing analysis method of the combination of theory with practice, we concluded that to accelerate new-type professional farmer cultivation, objects, contents and training system of professional farmer should be adjusted and refined; reserved professional farmer cultivation system should be developed and professional farmer cultivation should be combined with agriculture technology extension. We hope the problems, causes and solutions discussed here will be of some help to the future development of professional farmer cultivation in China.
\end{abstract}

Keywords-agriculture modernization; new-type professional farmer; cultivation; professional farmer training

Cultivation of new-type professional farmer is the base for modern agriculture development and urban-rural integration. Practice of developed countries shows, generally speaking $80 \%$ of farmland is cultivated by professional farmers, and $50 \%$ of agriculture production value is provided by them. In United States, in order to cultivate new-type professional farmer, US government offered preferential treatment such as subsidies and credit and loan to cement dominant position of agriculture[1]. To catch up with developed countries we have a long way to go. Cultivating new-type professional farmer is the crucial needs of China. Professional farmer are 'modernized professionals', and are the keys to solve the problems raised by 'farmer shortage' [2]. Professional farmer cultivation should be carried out from three dimension including specialization, industrialization and systematization [3]. Government should be responsible for the cultivation of new-type professional farmer and should offer various protective methods for the development of professional farmer cultivation [4]. For the following part, discussion will be made to find out ways for accelerating cultivation of new-type professional farmers.

\section{The Cultivation Of NeW-Type Professional FARMer Is OF VITAL IMPORTANCE}

A. Cultivate new-type professional farmer is required to guarantee food safety and effective supply of crucial agricultural products

Moderate scale operation of agriculture is the solution to low productivity and low economic benefits in agriculture industry, and is the guarantee for food safety in China [5] Farmers, especially farmers with high qualification, are required to support the scale operation of agriculture industry. Accelerating cultivation and motivation of new-type professional farmer will facilitate problem solving for agriculture industry and effectively improve food safety.

B. Cultivate new-type professional farmer will facilitate transformation and upgrading of modern agriculture industry

Presently, China is in the critical period of transforming from traditional agriculture industry to modern agriculture industry. New-type professional farmer plays the principal part in the transformation and upgrading process[6]. Cultivation of new-type professional farmer with high qualification in the field of agriculture technology and management operation is the right answer for all questions.

\section{Cultivate new-type professional farmer will facilitate the} establishment of new-type agricultural operation system

With reform progressing, number and quality of farmer is in continuing declining. Establishment of new-type agricultural operation system guarantees the cultivation of 'qualified successor' for agriculture development.

\section{New Problems In Cultivation OF NeW-Type} PROFESSIONAL FARMERS DURING THE “13TH FIVE YEARS”

\section{A. The objects chosen for cultivating professional farmer is unscientific}

The cultivation objects are rural labors below 45 years of age and with urban household registration. However the realistic is that most of the rural labor who own farmland have already transferred to non-agricultural industries, non-local 
labors become the subject of agriculture production and operation. Most of workers in agriculture enterprises are untrained labors in the right age, unqualified according to policy requirements. Surveys indicate that less than $1 / 10$ of total number of labors with urban household registration and within the age limitation is now still working in agriculture industry, part of rural labor who have already transferred to non-agricultural industries are still included in training plans, thus non-local labors who are presently working in agriculture industry are unqualified to take part in the training, while labors who are qualified to be trained have no place to apply the technique learned from the training in their work.

\section{B. The content of professional farmer training is in lack of adequacy}

The content of training projects like pervasive training of practical agricultural technique and vocational agricultural certificate training emphasizes more on general skill training. Which means the training content has not been adjusted dynamically with order of priority and according to the needs of modern agriculture development, training content can't match the needs of market demand. Professional farmer training is in lack of market adequacy, and thus achievement transformation is limited.

\section{Reserved cultivation of professional farmer is insufficient}

Cultivation of professional farmer is a system engineering that in need of policy orientation and motivation. At present, the rewards from agricultural industry are still lower than that of non-agricultural industry. Rural labors still tend to transfer from agricultural industry to non-agricultural industry, even graduates of agriculture universities are unwilling to work in agricultural industry. New generation farmers should make the principal part of all professional farmers, however absorbing capacity of government policies is not enough, and farmerfriendly social atmosphere hasn't been created, the nonagricultural tendency has not yet been changed. Training policy hasn't been specially focused on new-generation graduates from college or vocational college and returned migrant workers, and hasn't reached to elementary education and vocational education; the reserved cultivation of professional farmer is insufficient.

\section{Cultivation system of professional farmer is incomplete}

Firstly, training facility and training condition is poor. As the main undertaker of professional farmer training, agricultural broadcasting and television school, and agricultural mechanization school have been always under-invested. Training facility and training condition in these schools can't meet the government standards. Schools are in lack of teachers, teaching facilities, training locations, related tools, practice bases, and accrediting bodies. Secondly, number of training teacher is insufficient. Training teachers are generally come from municipal agricultural business sections, agricultural research institutions and district agricultural technicians. These teachers present two characteristics. One characteristic is that knowledge of aged teachers is outmoded. The other characteristic is that knowledge of young teacher is unpractical and unsystematic. Besides, due to the low rewards, teachers are not motivated to participate in the training. Thirdly, class hour arranged for training is unreasonable. It requires 300 class hours to complete elementary training and 240 class hours to complete secondary training. Since farmers always choose to take on-the-job training, which means they are unable to spare too much time for training. Up to now, no one has already completed training lessons of whole 300 class hours. Fourthly, training system needed to be integrated. Training tasks are separately assigned by the municipal government to Human Resource and Social Security Bureau and Council of Agriculture, and then reassigned by these two departments to the same undertakers of next level, which causes many management confusions.

\section{Suggestion for Promotion of Professional FARMer CUltivation IN THE PERIOD OF “13TH Five Years”}

\section{A. Adjust objects and contents of training, refine professional farmer training system}

Firstly, accurately capture the training objects. The qualification recognization should extend beyond farmer with urban household registration to include eternal population who are resident and have signed mid-term or long-term farmland operating contract, and new-generation farmer who haven't achieved transferred employment into training projects. Secondly, reasonably arrange training schedule. Training schedule should be arranged in accordance with farming season and characteristic of agriculture production. Flexible training arrangement should be carried out to make full use of shortterm, mid-term and long-term training to facilitate farmers' participation. Shot-term training should be emphasized. Thirdly, reasonably adjust training content. Training content should be realistic, practical and effective, and should emphasize on pervasive training of practical skills, and consider professional agriculture certificate training and adult education for higher diploma. Practical skill training should focus on type of work and skill that is in urgent needs. Fourthly, appropriately choose the training methods. Practical operation should be the main content of training, while training methods such as: investigate study, panel discussion and theory explanation should also be included. Training methods like classroom teaching, on-site explanation, on-line training and expert consultation should be combining together during the training.

\section{B. Combine cultivation and support together, refine professional farmer training system}

Firstly, integrate education and training system. Unify agricultural and farmer training system, integrate together the agricultural training of agriculture department and the rural labor training of human resource and social security department. Secondly, select and establish training institutions. Utilize public welfare and profit-making social resources together as a whole, select training institutions in the principles of justice, openness and fairness, increase financial support to the selected training institutions. Thirdly, establish training bases. Select some better-basis institutions from agricultural science and technology innovation demonstration bases, agricultural enterprises, cooperative organization of farmers, agriculture parks, agri-technique extension center, etc., and use 
them as training bases for farmers, develop policies to regulate practical teaching activities. Fourthly, support entrepreneurship of new-type professional farmer. Cultivate new-type professional farmers with qualification to become new-type agricultural business subject during "the 13th five years". Preferential policies made by governments of various levels related to land circulation, agricultural infrastructure construction, and major agricultural project should tilt to professional farmers to support entrepreneurship of new-type professional farmer in the field of agriculture.

\section{Develop reserved professional farmer cultivation system, improve professional orientation towards agriculture}

Firstly, enhance education of elementary knowledge in agriculture; cultivate agriculture identity of adolescent in rural areas. Add agri-technique skill courses in the stage of compulsory education in rural areas; cultivate students' agriculture attachment and agricultural skills. Secondly, promote university specialty construction in the field of agriculture products marketing and rural broker. Education administration department should be responsible to orient universities to set up majors and courses related to agriculture to promote specialized personnel training. Thirdly, increase amount of tuition waiver, encourage graduates to work in agriculture industry. Tuition should be refunded if the graduates of agriculture universities are employed in agriculture industry. Subsidy equals to the amount of tuition should be provided to motivate graduates who hold permanent urban residential registrations and are willing to work on frontline agriculture department. Fourthly, establish retirement and social insurance system for professional farmers. Government should establish retirement system for professional farmers with professional certificate. Professional farmers conducting independent production and operation activities and professional farmers employed by agricultural enterprises should all be included in the system. Government should provide premium subsidy to make it a priority to establish endowment insurance system for professional farmers.

\section{Combine professional farmer cultivation with agricultural technology extension, cultivate technological business subject in the field of agriculture}

Firstly, bidirectionally cultivate professional farmer. On one hand, professional farmer can be trained to be agritechnique extension expert. On the other hand, operators of agricultural science and Technology Park, agri-technique extension expert can also be cultivated to be new-type professional farmer. Secondly, reform extension mode of agritechnique. Government-led agri-technique extension mode has already become unsuitable for market development. Emphasis of agri-technique extension policy should change from supply of technique to demand of technique, to orient agricultural proprietors to transform scientific and technological achievements or purchase technique services autonomously. Government should provide subsidy to support this change. Thirdly, intensify policy support for private agricultural science and technology enterprises. Private agricultural science and technology enterprises can transform scientific and technological achievements more efficiently; science and technology funds provided by government should be inclined to private institutions, to offer equal opportunity to private institutions as to stated-own institutions, and to create a newtype of agricultural business characterized by agri-technique innovation and new-technology extension.

\section{SUMMARY}

Cultivating new-type professional farmer is the urgent needs of modern agriculture development and modernization construction of rural areas under the new situation. How to effectively cultivate new-type professional farmer is the question answered here. From discussion above, following conclusions are drawn by references to abundant materials and outcomes of other experts:

Firstly, objects and contents of training should be adjusted; professional farmer training system should be refined, in order to promote professional farmer cultivation.

Secondly, cultivation and support should be combined together, in order to refine professional farmer training system.

Thirdly, reserved professional farmer cultivation system should be developed, in order to improve professional orientation towards agriculture.

Fourthly, professional farmer cultivation should be combined with agriculture technology extension, in order to cultivate technological business subject in the field of agriculture.

In conclusion, with the progressing of modern agriculture development and new rural reconstruction, cultivation of professional farmer will become a more and more important problem faced by government and our society. Attention should be focus constantly on the issues pertinent to new-type professional farmer cultivation.

\section{REFERENCES}

[1] Li Guoxiang, Yang Zhengzhou. Implications From Cultivation Policy of New-Type Professional farmer in USA. Issues in Agricultural Economy, Vol.5(2013), p. 93-97

[2] Ma Jianfu. Responsibility and Action Strategy of Professional Education for Cultivation of New-Type Professional Farmer. Research in Educational Development, Vol.Z1 (2015), p. 73-79.

[3] Tong Jie, Li Hongwei, Qu Xihua. Research on Direction and System Construction for Cultivation of New-Type Professional Farmer in China. Research on Financial and Economic Issues, Vol.4 (2015), p. 91-96.

[4] Chen Xinran. Research on Security Policy of New-Type Professional Farmer in Tianjin. Tianjin University of Technology, (2016).

[5] Xia Yiguo, Gong Chunsheng. Moderate Scale Operation of Agriculture and New-Type Professional Farmer Cultivation under the Prospective of Food Safety in China. Issues in Agricultural Economy, Vol.5 (2015), p. 56-64+111.

[6] Tang Xianling. Consideration on the Cultivation of New-type Professional Farmer during Transformation and Upgrading of Agriculture. Agricultural Economy, Vol.1 (2016), p. 54-56. 